\title{
Inhibition of phosphodiesterase 4 reduces ethanol intake and preference in C57BL/6J mice
}

\author{
Yuri A. Blednov, Jillian M. Benavidez, Mendy Black and R. Adron Harris*
}

Waggoner Center for Alcohol and Addiction Research, The University of Texas at Austin, Austin, TX, USA

\section{Edited by:}

Richard Lowell Bell, Indiana

University School of Medicine, USA

Reviewed by:

Asha Suryanarayanan, Manchester

College School of Pharmacy, USA

Sunil Sirohi, Washington State

University, USA

*Correspondence:

R. Adron Harris, Waggoner Center for Alcohol and Addiction Research, The University of Texas at Austin, 2500 Speedway, Austin, TX 78712 USA

e-mail: harris@austin.utexas.edu
Some anti-inflammatory medications reduce alcohol consumption in rodent models. Inhibition of phosphodiesterases (PDE) increases CAMP and reduces inflammatory signaling. Rolipram, an inhibitor of PDE4, markedly reduced ethanol intake and preference in mice and reduced ethanol seeking and consumption in alcohol-preferring fawn-hooded rats (Hu et al., 2011; Wen et al., 2012). To determine if these effects were specific for PDE4, we compared nine PDE inhibitors with different subtype selectivity: propentofylline (nonspecific), vinpocetine (PDE1), olprinone, milrinone (PDE3), zaprinast (PDE5), rolipram, mesopram, piclamilast, and CDP840 (PDE4). Alcohol intake was measured in C57BL/6J male mice using 24-h two-bottle choice and two-bottle choice with limited (3-h) access to alcohol. Only the selective PDE4 inhibitors reduced ethanol intake and preference in the 24-h two-bottle choice test. For rolipram, piclamilast, and CDP840, this effect was observed after the first $6 \mathrm{~h}$ but not after the next $18 \mathrm{~h}$. Mesopram, however, produced a long-lasting reduction of ethanol intake and preference. In the limited access test, rolipram, piclamilast, and mesopram reduced ethanol consumption and total fluid intake and did not change preference for ethanol, whereas CDP840 reduced both consumption and preference without altering total fluid intake. Our results provide novel evidence for a selective role of PDE4 in regulating ethanol drinking in mice. We suggest that inhibition of PDE4 may be an unexplored target for medication development to reduce excessive alcohol consumption.

Keywords: alcohol, two-bottle choice, PDE inhibitors, rolipram, mesopram, piclamilast, CDP840

\section{INTRODUCTION}

Alcoholism is one of the most expensive (more than $\$ 185$ billion/year in the US) and damaging chronic diseases (Bouchery et al., 2011), yet there are only three FDA-approved drugs for alcohol dependence (disulfiram, naltrexone, and acamprosate) (Johnson et al., 2007). Disulfiram blocks the enzyme acetaldehyde dehydrogenase, preventing formation of acetic acid from acetaldehyde (Heilig and Egli, 2006). Naltrexone blocks mu opioid receptors thought to be responsible for the rewarding effects of alcohol, thereby decreasing alcohol craving (Bouza et al., 2004); however, naltrexone was only effective in a subpopulation of recovering alcoholics. Acamprosate is thought to act by decreasing glutamatergic activity, reducing the negative effects associated with alcohol withdrawal. Treatment options are varied but limited, and there is a high rate of relapse for all existing treatments.

Current evidence suggests that brain immune or proinflammatory signaling is linked to alcohol action (Crews, 2012; Mayfield et al., 2013). Long-lasting increases in levels of several cytokines in mouse brain, including monocyte chemoattractant protein-1, MCP-1 (also known as chemokine C-C motif ligand 2, CCL2), were observed after pretreatment with high doses of ethanol followed by injection of lipopolysaccharide (LPS)

Abbreviations: PDE, phosphodiesterases; cAMP, $3^{\prime}, 5^{\prime}$-cyclic adenosine monophosphate; cGMP, $3^{\prime}, 5^{\prime}$-cyclic guanosine monophosphate.
(Qin et al., 2008). Interestingly, a similar increase in MCP1 (CCL2) was found in brains of human alcoholics (He and Crews, 2008), and deletion of $\mathrm{Ccl} 2$ or its receptor decreased alcohol consumption in mice (Blednov et al., 2005). Knockout of immune/inflammatory genes in mice, which were selected based on meta-analyses of genes and functional pathways involved in regulation of alcohol drinking in mice (Mulligan et al., 2006), rats (Kimpel et al., 2007), or humans (Liu et al., 2006, 2007; Flatscher-Bader et al., 2008), reduced ethanol intake and preference, further supporting immune pathways in regulating alcoholmediated behaviors (Blednov et al., 2012). Our research suggests that cytokines (perhaps via endotoxins) promote persistent and excessive alcohol consumption, which may in turn promote further inflammatory responses, producing a positive feedback loop leading to excessive alcohol consumption (Blednov et al., 2011). Furthermore, even a single injection of LPS induces a long-lasting decrease in dopamine neuron firing in the ventral tegmental area, suggesting that cytokine signaling can regulate reward circuitry (Blednov et al., 2011). It is also noteworthy that chronic alcohol consumption and LPS treatment can produce similar changes in mouse brain transcriptomes (Osterndorff-Kahanek et al., 2013).

Phosphodiesterases (PDEs) are a superfamily of enzymes catalyzing the hydrolysis of $3^{\prime}, 5^{\prime}$-cyclic adenosine monophosphate (cAMP) and $3^{\prime}, 5^{\prime}$-cyclic guanosine monophosphate (cGMP) to their inactive $5^{\prime}$-AMP and $5^{\prime}$-GMP forms, respectively. Increased 
cAMP and/or cGMP, resulting from inhibition of PDE, reduces inflammatory signaling (Page and Spina, 2011; Jin et al., 2012). Cyclic nucleotides are known to play pivotal roles in a number of cellular functions, including immune and inflammatory responses, cardiac activities, smooth muscle relaxation, depression and cognition. The anti-inflammatory actions of PDE inhibitors are beneficial in treating chronic obstructive pulmonary disease and asthma (Jin et al., 2012; Keravis and Lugnier, 2012). PDEs are encoded by 21 genes, grouped into 11 families, according to their structural similarity. Each gene encodes multiple protein products generated by alternative splicing and/or multiple promoters, resulting in more than 50 different PDE proteins that may be produced in mammalian cells (Bender and Beavo, 2006).

Rolipram, an inhibitor of PDE4, markedly reduced alcohol intake and preference in mice (Hu et al., 2011) and reduced alcohol seeking and consumption in alcohol-preferring fawn-hooded rats (Wen et al., 2012). Rolipram also reduced cocaine conditioned place preference and self-administration (Knapp et al., 1999; Thompson et al., 2004) and inhibited neuroimmune signaling (Zhu et al., 2001). Rolipram and other PDE4 inhibitors have been investigated as potential therapeutics in diverse CNS disease models, including depression, anxiety, schizophrenia, Parkinson's, and Alzheimer's disease (Halene and Siegel, 2007; Kanes et al., 2007; Smith et al., 2009). In this study, we compared the effects of various PDE inhibitors on alcohol consumption and preference in mice. We studied nine PDE inhibitors with different selectivity profiles (Shahid et al., 1991; Raeburn and Karlsson, 1993; Ashton et al., 1994; Meskini et al., 1994; Sugioka et al., 1994; Perry et al., 1998; Dinter et al., 2000): propentofylline (nonspecific); vinpocetine (PDE1); olprinone, milrinone (PDE3); zaprinast (PDE5); rolipram, mesopram, piclamilast, and CDP840 (PDE4) and examined their effects in two different ethanol consumption tests.

\section{MATERIALS AND METHODS \\ MICE}

Male C57BL/6J mice were taken from a colony maintained at The University of Texas at Austin (original breeders were purchased from Jackson Laboratories, Bar Harbor, ME). Mice were group-housed four or five to a cage. Food and water were available ad libitum. The vivarium was maintained on a 12:12 h light/dark cycle with lights on at 7 a.m. The temperature and humidity of the room were kept constant. Behavioral testing began when the mice were at least 2 months old. All experiments were conducted in isolated behavioral testing rooms in the Animal Resources Center at The University of Texas with reversed light cycle to avoid external distractions. Before beginning experiments, mice were moved to their experimental room and remained there for at least 2 weeks to adapt to the new light cycle. All experiments were approved by the Institutional Animal Care and Use Committee at The University of Texas at Austin.

\section{BASELINE DRINKING}

In both ethanol consumption tests (described below), mice first consumed $15 \%$ ethanol for at least 3 weeks. After this period, ethanol consumption was measured for at least 4 days to ensure stable consumption. The criterion for stable consumption was similar values for days 1-2 and days 3-4. For the 24-h two-bottle choice test, ethanol intake was then measured after saline injection for 2 days, and mice were grouped to provide similar levels of ethanol intake and preference based on the first $6 \mathrm{~h}$ of consumption during these 2 days. Ethanol and total fluid intake were presented as $\mathrm{g} / \mathrm{kg} / 6 \mathrm{~h}$. Measurements made after the next $18 \mathrm{~h}$ were presented as percent of corresponding control (values obtained after the next $18 \mathrm{~h}$ during the first 2 days of saline injection). In the drinking in the dark (DID) test, mice were grouped to provide similar levels of ethanol intake and preference based on $3 \mathrm{~h}$ of consumption during the first 2 days of saline injections. Ethanol and total fluid intake were presented as $\mathrm{g} / \mathrm{kg} / 3 \mathrm{~h}$. From day 3 , mice were injected once daily with either saline or drugs for up to 10 days, depending on the drug.

\section{DRUG ADMINISTRATION}

Propentofylline $(5 \mathrm{mg} / \mathrm{kg})$, vinpocetine $(10 \mathrm{mg} / \mathrm{kg})$, and piclamilast $(1 \mathrm{mg} / \mathrm{kg})$ were injected i.p. Olprinone $(0.5 \mathrm{mg} / \mathrm{kg})$, milrinone $(0.5 \mathrm{mg} / \mathrm{kg})$, mesopram $(5 \mathrm{mg} / \mathrm{kg})$, rolipram ( 1 and $5 \mathrm{mg} / \mathrm{kg})$, CDP840 (10 and $25 \mathrm{mg} / \mathrm{kg}$ ), and zaprinast $(10 \mathrm{mg} / \mathrm{kg}$ ) were administered p.o. Drugs were purchased from Sigma-Aldrich (St. Louis, MO) or Tocris Bioscience (Minneapolis, MN). All drugs were freshly prepared as suspensions in saline with $4-5$ drops of Tween- 80 and injected in a volume of $0.05 \mathrm{ml} / 10 \mathrm{~g}$ of body weight 30-60 min before drinking experiments. Saline containing 4-5 drops of Tween-80 was injected in the same volume for control groups. Doses of drugs and routes of administration were based on published data showing anti-inflammatory activity in vivo (Yamada et al., 1998; Dinter et al., 2000; Prickaerts et al., 2004; Di Paola et al., 2011; Xiao et al., 2011; Hotte et al., 2012). If the drug was not effective within 4 days, a higher dose was then tested.

\section{ETHANOL DRINKING-24-h TWO-BOTTLE CHOICE}

The two-bottle choice protocol was carried out as previously described (Blednov et al., 2001). Bottles were weighed twice daily (see below). Food was available ad libitum, and mice were weighed every 4 days beginning on day 1 . Bottle positions were changed daily to control for position preferences. Ethanol consumption ( $\mathrm{g} / \mathrm{kg}$ body weight/time) was calculated for each mouse. Ethanol (15\%) was used in all experiments, and mice had unlimited access to one bottle of water. Ethanol intake was measured $6 \mathrm{~h}$ after the beginning of the drinking test and again after the next $18 \mathrm{~h}$. Measurements of ethanol intake, preference, and total fluid intake were averaged over 2 days with different bottle positions. Each point in the graphs (e.g., days 2, 4, 6, 8, 10) represents the average of 2 days of measurement. For example, day 2 is the average of days $1-2$ and day 4 is the average of days $3-4$.

\section{ETHANOL DRINKING - LIMITED ACCESS IN THE DARK PHASE (TWO-BOTTLE CHOICE DID)}

This was similar to the one-bottle DID test previously described (Rhodes et al., 2005) except that two bottles containing either $15 \%$ ethanol or water were used (Blednov and Harris, 2008). The ethanol and water bottles remained in place for $3 \mathrm{~h}$. 


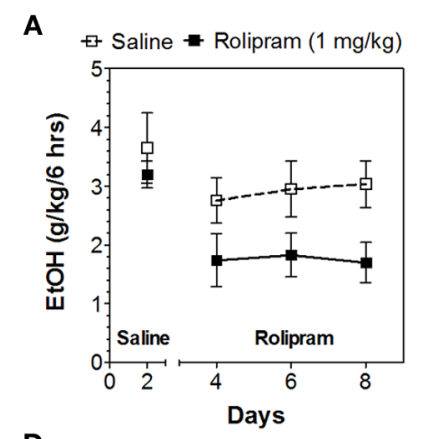

D

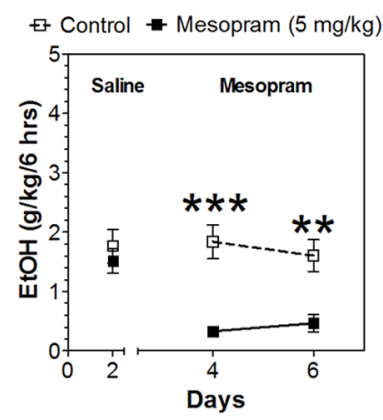

G

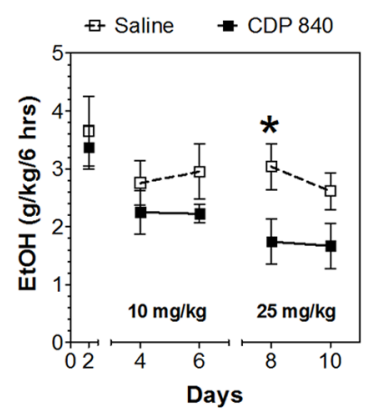

J

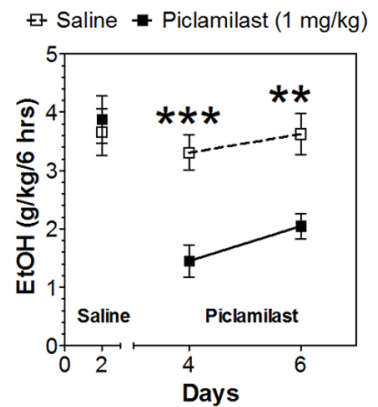

B

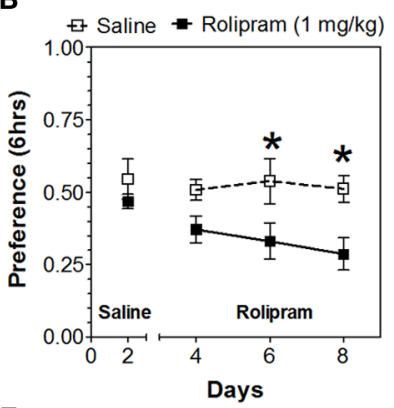

E

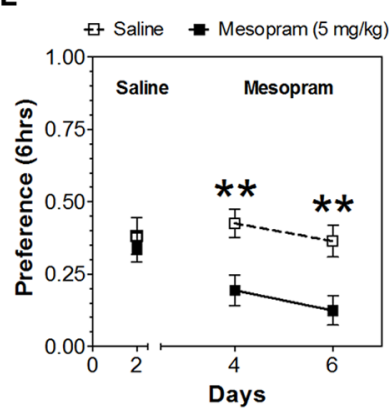

H

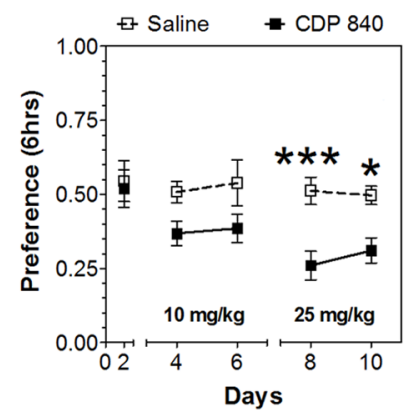

$\mathbf{K}$

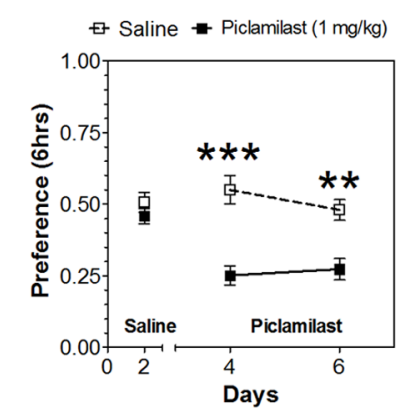

C

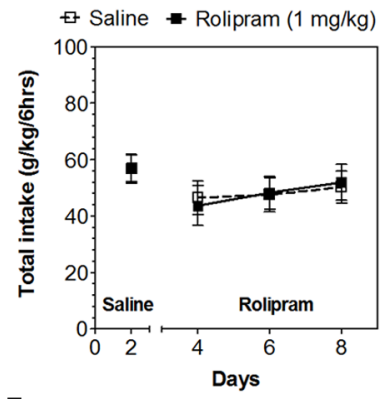

$\mathbf{F}$

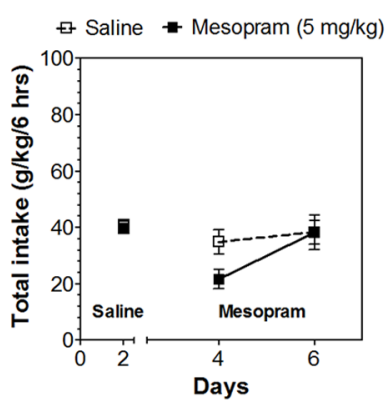

I

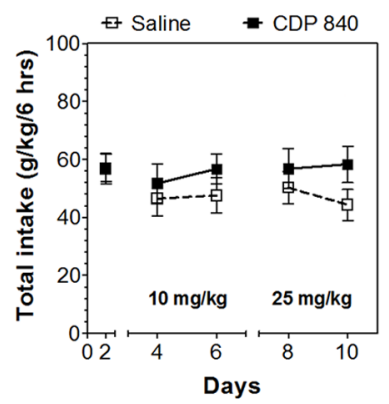

$\mathbf{L}$

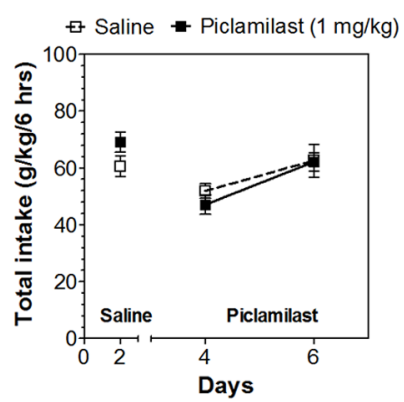

FIGURE 1 | PDE4 inhibitors reduce alcohol intake during the first $6 \mathrm{~h}$ of the 24-h two-bottle choice paradigm. Ethanol consumption is presented as g/kg/6 h: (A) Rolipram (D) Mesopram (G) CDP840 (J) Piclamilast. Preference for ethanol: (B) Rolipram (E) Mesopram (H) CDP840 (K) Piclamilast. Total fluid intake (g/kg/6 h): (C) Rolipram (F) Mesopram (I) CDP840 (L) Piclamilast. Data were analyzed by Two-Way ANOVA with repeated measures followed by Bonferroni's test for multiple comparisons. ${ }^{*} p<0.05$; ${ }^{* *} p<0.01$; *** $p<0.001$ compared to control ( $n=6$ per group; $\mathrm{EtOH}=$ ethanol).
After their removal, mice had unlimited access to one bottle of water. Bottle positions during 3-h access were changed daily to control for potential side preferences. The ethanol and water bottles were weighed before placing and after removal from experimental cages. Drinking began $3 \mathrm{~h}$ after lights off and continued for $3 \mathrm{~h}$. Measurements of ethanol intake, preference, and total fluid intake were averaged over 2 days with different bottle positions. Each point in the graphs (e.g., days $2,4,6,8,10)$ represents the average of 2 days of measurement. 


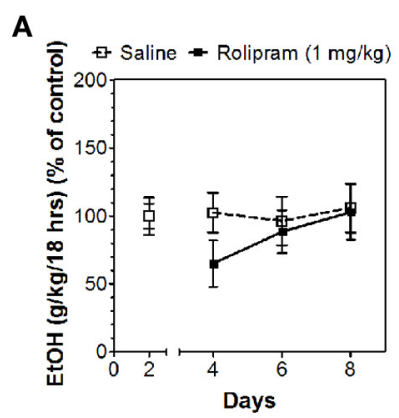

D

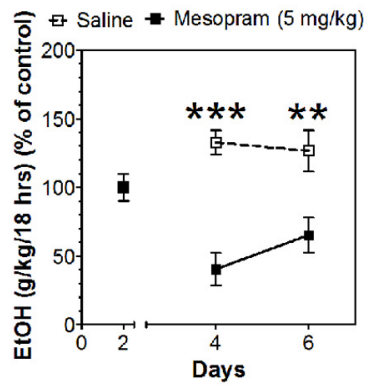

G

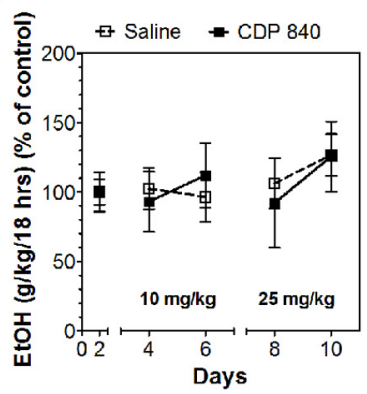

J

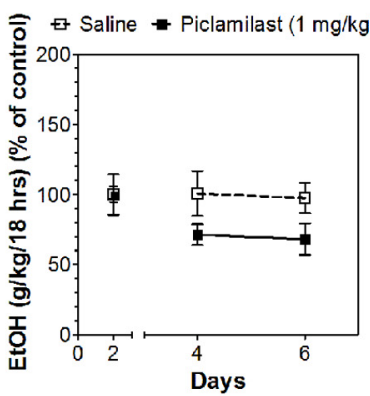

B

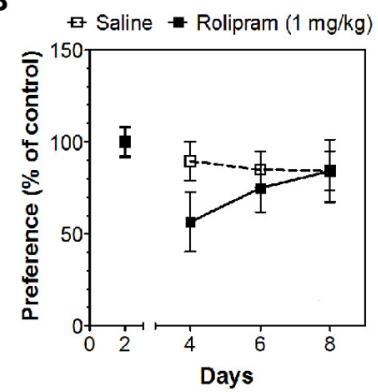

E

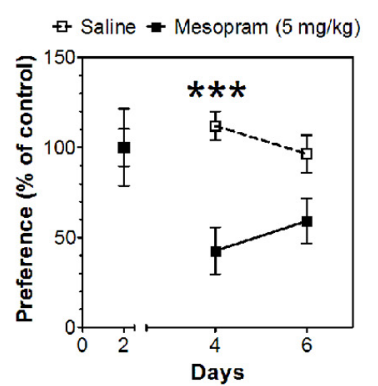

H

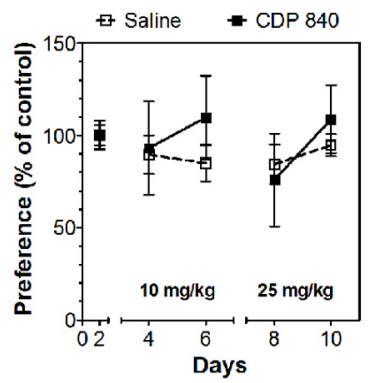

K

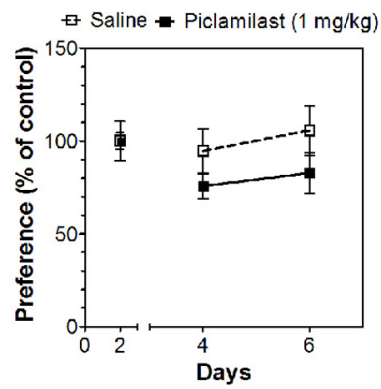

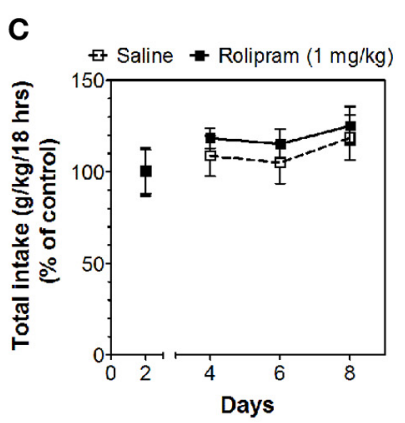

$\mathbf{F}$
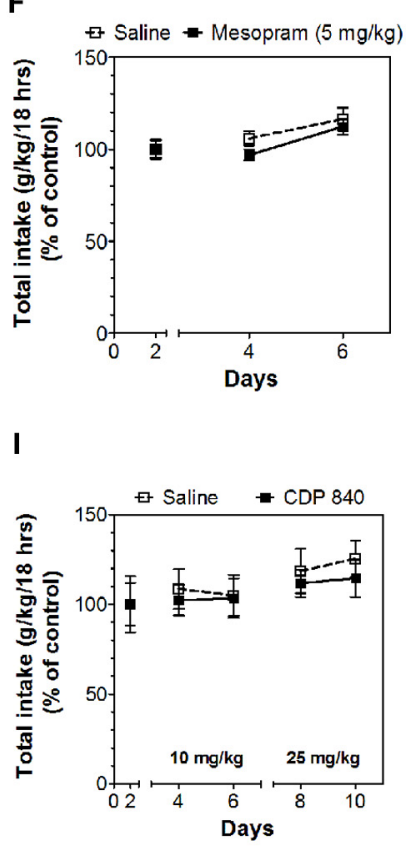

$\mathbf{L}$

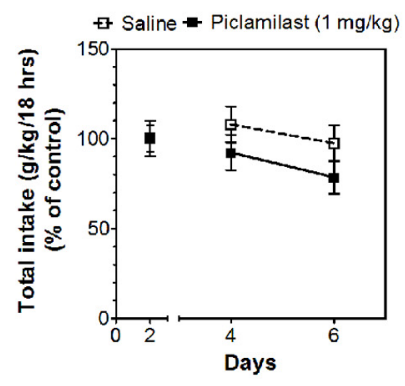

FIGURE 2 | Effects of PDE4 inhibitors on alcohol intake during the next $\mathbf{1 8} \mathrm{h}$ of the 24-h two-bottle choice paradigm. Ethanol consumption is presented as g/kg/18 h: (A) Rolipram (D) Mesopram (G) CDP840 (J)

Piclamilast. Preference for ethanol: (B) Rolipram (E) Mesopram (H) CDP840 (K)
Piclamilast. Total fluid intake (g/kg/18 h): (C) Rolipram (F) Mesopram (I) CDP840 (L) Piclamilast. Data were analyzed by Two-Way ANOVA with repeated measures followed by Bonferroni's test for multiple comparisons. ${ }^{* *} p<0.01$;

*** $p<0.001$ compared to control ( $n=6$ per group; $\mathrm{EtOH}=$ ethanol).

\section{STATISTICAL ANALYSIS}

Data are reported as the mean \pm s.e.m. The statistics software program GraphPad Prism (Jandel Scientific, Costa Madre, CA) was used throughout. Two-Way repeated measures ANOVA with post-hoc Bonferroni corrections and Student's $t$-tests were performed.

\section{RESULTS}

\section{TWO-BOTTLE CHOICE WITH CONTINUOUS ACCESS TO ALCOHOL}

In the 24-h two-bottle choice continuous access test, all four PDE4 inhibitors (rolipram, mesopram, piclamilast, CDP840) reduced alcohol intake and preference after the first $6 \mathrm{~h}$ without affecting total fluid intake (Figure 1; for complete statistical 
A

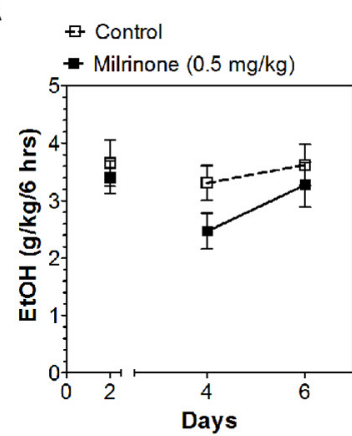

D $¥$ Saline

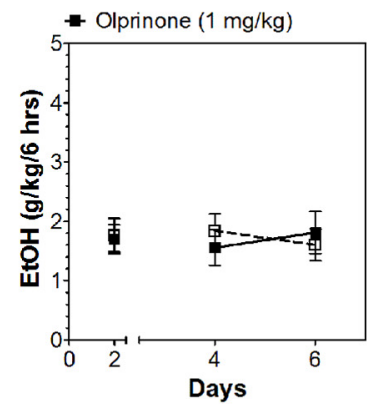

G $\quad$ Saline

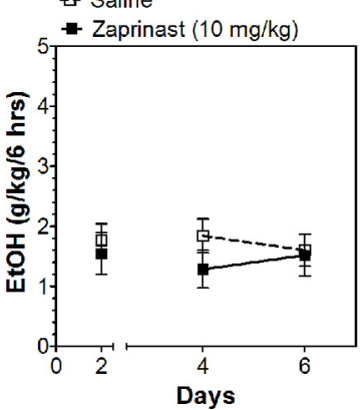

B

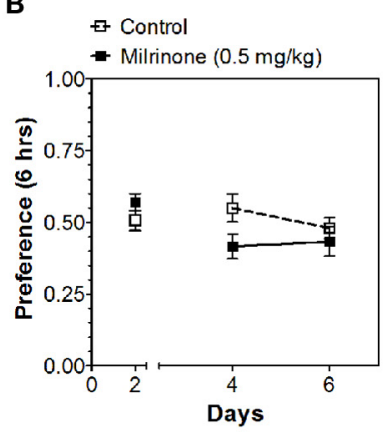

E $\quad$ Saline

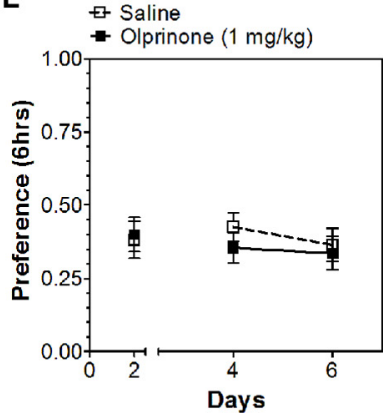

H $\quad$ t Saline

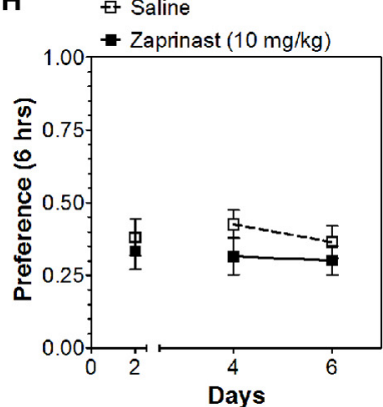

C

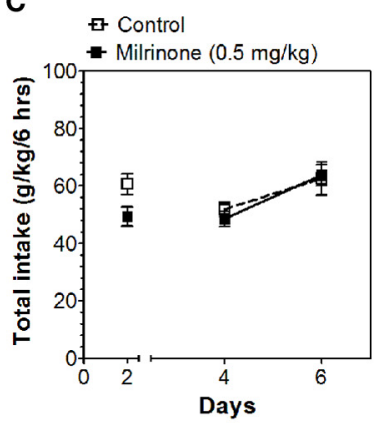

F $\quad$ S Saline

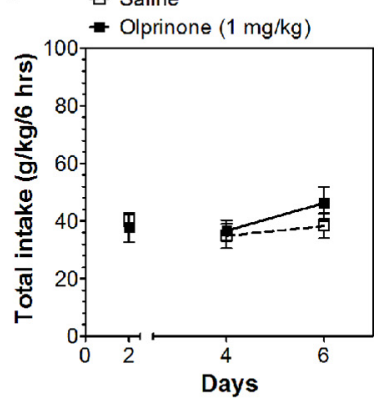

I

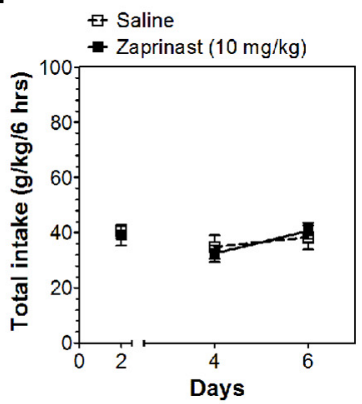

FIGURE 3 | PDE3 and PDE5 inhibitors do not alter alcohol intake during the first $6 \mathrm{~h}$ of the 24-h two-bottle choice paradigm. Ethanol consumption is presented as $\mathrm{g} / \mathrm{kg} / 6 \mathrm{~h}$ : (A) Milrinone (D) Olprinone (G) Zaprinast. Preference for ethanol: (B) Milrinone (E) Olprinone (H)
Zaprinast. Total fluid intake (g/kg/6 h): (C) Milrinone (F) Olprinone (I) Zaprinast. Data were analyzed by Two-Way ANOVA with repeated measures followed by Bonferroni's test for multiple comparisons ( $n=6$ per group; $\mathrm{EtOH}=$ ethanol). analyses see Data Sheet 1). For rolipram, piclamilast, and CDP840, this effect was not long lasting and was not observed after the next $18 \mathrm{~h}$ of ethanol consumption (Figure 2; Data Sheet 2). Mesopram, however, produced a long-lasting reduction of ethanol intake and preference (measured after the next $18 \mathrm{~h}$ of ethanol consumption) (Figures 2D,E; Data Sheet 2).

Inhibitors of other classes of PDEs (olprinone, milrinone, zaprinast, propentofylline, and vinpocetine) had no effect on ethanol consumption in the continuous access test at either time point (Figures 3-5; Data Sheets 3, 4).

\section{TWO-BOTTLE CHOICE WITH LIMITED ACCESS TO ALCOHOL}

Because of the selective reduction by PDE4 inhibitors in continuous access drinking, only this subtype was studied in the limited access test. In contrast to continuous access, rolipam $(1 \mathrm{mg} / \mathrm{kg})$ did not change consumption in limited access
(Figures 6A-C; Data Sheet 5); however, $5 \mathrm{mg} / \mathrm{kg}$ rolipram as well as mesopram, piclamilast, and CDP840 strongly reduced alcohol intake (Figures 6A,D,G,J; Data Sheet 5). Of these inhibitors, CDP840 also reduced alcohol preference (Figures 6H,I), whereas rolipram, mesopram, and piclamilast failed to reduce alcohol preference (Figures 6B,E,K) because they reduced total fluid intake (Figures 6C,F,L; Data Sheet 5).

\section{DISCUSSION}

Rolipram was previously shown to reduce ethanol intake and preference in mice (Hu et al., 2011) and rats (Wen et al., 2012) in 24-h two-bottle choice tests, which is consistent with our results in mice. We further demonstrate that other selective PDE4 inhibitors (but not other classes of PDE inhibitors) reduce intake and preference in the 24 -h two-bottle choice paradigm. Like rolipram, CDP840 and piclamilast transiently reduce intake, 
A

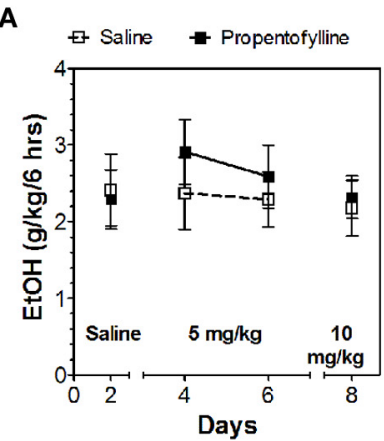

D

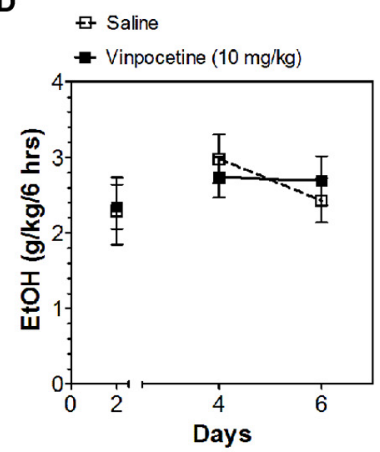

B

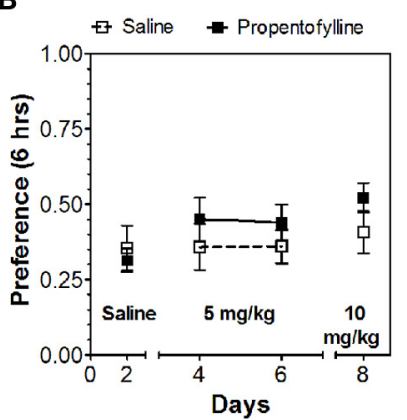

E

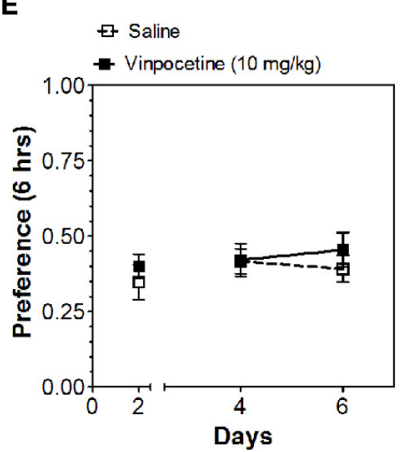

C

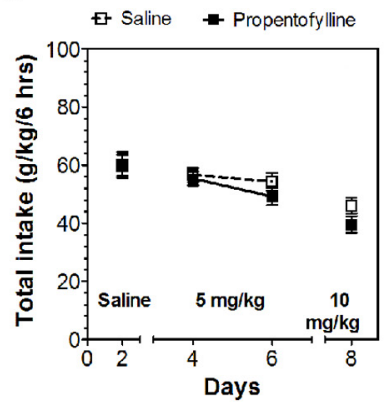

$\mathbf{F}$

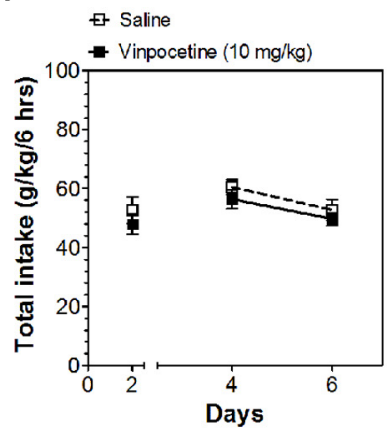

FIGURE 4 | PDE1 inhibitor vinpocetine and nonspecific inhibitor propentofylline do not alter alcohol intake during the first $6 \mathrm{~h}$ of the 24-h two-bottle choice paradigm. Ethanol consumption is presented as $\mathrm{g} / \mathrm{kg} / 6 \mathrm{~h}$ : (A) Propentofylline (D) Vinpocetine. Preference for ethanol: (B)
Propentofylline (E) Vinpocetine. Total fluid intake ( $\mathrm{g} / \mathrm{kg} / 6 \mathrm{~h}$ ): (C) Propentofylline (F) Vinpocetine. Data were analyzed by Two-Way ANOVA with repeated measures followed by Bonferroni's test for multiple comparisons ( $n=6$ per group; $\mathrm{EtOH}=$ ethanol). whereas mesopram produces long-lasting decreases. Hu et al. (2011) did not report transient effects of rolipram, but they injected it i.p. twice daily, whereas we used a once daily oral administration. CDP840 also reduces ethanol intake and preference in the limited access test, whereas the other PDE4 inhibitors do not alter preference. Reduction of ethanol and total fluid intake, without changes in preference, in the limited access test may be due to the sedative activity of PDE4 inhibitors ( $\mathrm{Hu}$ et al., 2011). Any sedative effects would be likely to interfere with drinking in this limited 3-h time period. However, mice in limited access or "binge" models may also display a different sensitivity to pharmacological intervention compared to mice undergoing continuous access (Crabbe et al., 2011). Furthermore, these two treatment paradigms induce different transcriptome signatures in mouse brain (Osterndorff-Kahanek et al., 2013). Other classes of inhibitors (nonspecific or PDE1, 3, or 5 inhibitors) had no effect on alcohol consumption in the continuous access test. Similar to our results with propentofylline, ibudilast (another nonspecific PDE inhibitor) did not change alcohol intake in non-dependent mice; however, ibudilast reduced drinking in alcohol-dependent mice and in alcohol-preferring $\mathrm{P}$ and HAD1 rats (Bell et al., 2013). Also, mice with genetic deletion of both adenylyl cyclase 1 (AC1) and AC8 exhibited decreased ethanol consumption and enhanced sensitivity to ethanol sedation (Maas et al., 2005). In contrast, mice lacking AC5 showed increased ethanol consumption and preference and reduced sensitivity to ethanol sedation (Kim et al., 2011).
It is important to note that the PDE inhibitors which did not alter alcohol consumption are nevertheless capable of exerting other CNS-dependent effects on behavior and neurophysiology. For example, olprinone and milrinone provided significant neuroprotection after cerebral ischemia/reperfusion injury in rats (Saklani et al., 2010; Genovese et al., 2011). Zaprinast and other PDE5 inhibitors improved memory (Prickaerts et al., 2004), and propentofylline improved learning and memory deficits induced by beta-amyloid protein (Yamada et al., 1998). Also, vinpocetine ameliorated hyperactivity in a mouse model of fetal alcohol spectrum disorder (Nunes et al., 2011).

Despite a long history of availability (since the late 1980's), PDE inhibitors are of limited clinical use because of lack of efficacy and/or gastroenterological side effects such as nausea and vomiting (Giembycz, 2008). One approach to mitigate the adverse effects is seeking agents with selectivity for PDE4 isoforms devoid of these effects. PDE4 isoenzymes are encoded by four genes (A, B, C, D), and it is believed that inhibition of PDE4D promotes emesis. Selective inhibition of PDE4A and/or PDE4B in pro-inflammatory and immune cells is believed to produce desired anti-inflammatory effects (Giembycz, 2008; Jin et al., 2012). PDE4B is of particular interest because it is localized in brain reward pathways (Cherry and Davis, 1999), and its expression is upregulated in mice with a genetic predisposition for high alcohol consumption (Mulligan et al., 2006). Rolipram inhibits PDE4 catalytic activity with micromolar potency but also binds to a high affinity (nanomolar) site on PDE4 (Schneider 
A

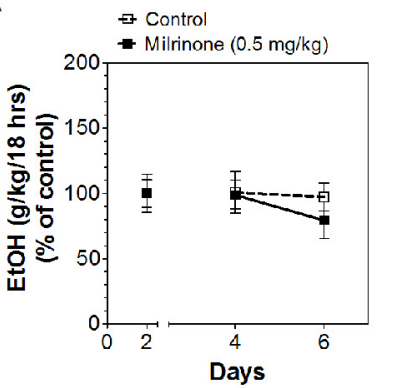

D
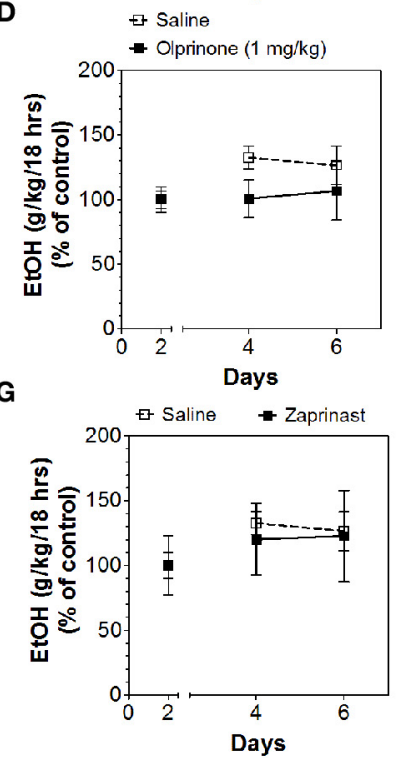

$\mathbf{J}$

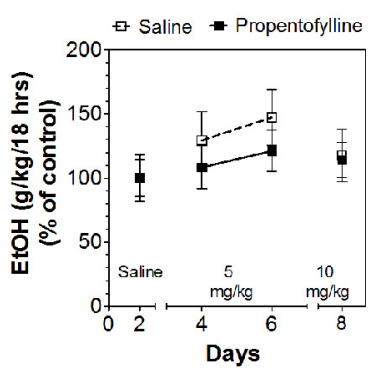

M

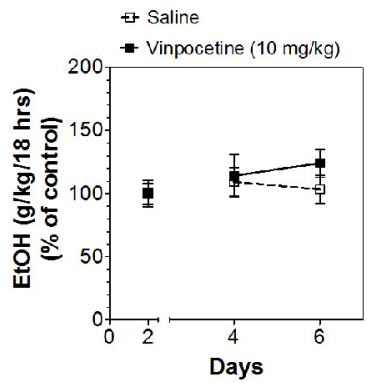

B

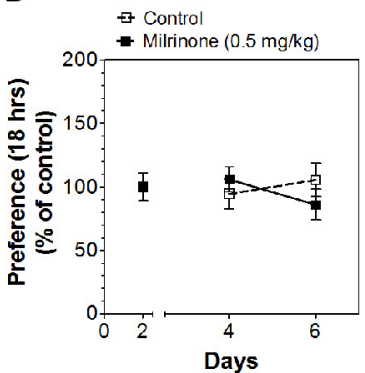

$\mathbf{E}$
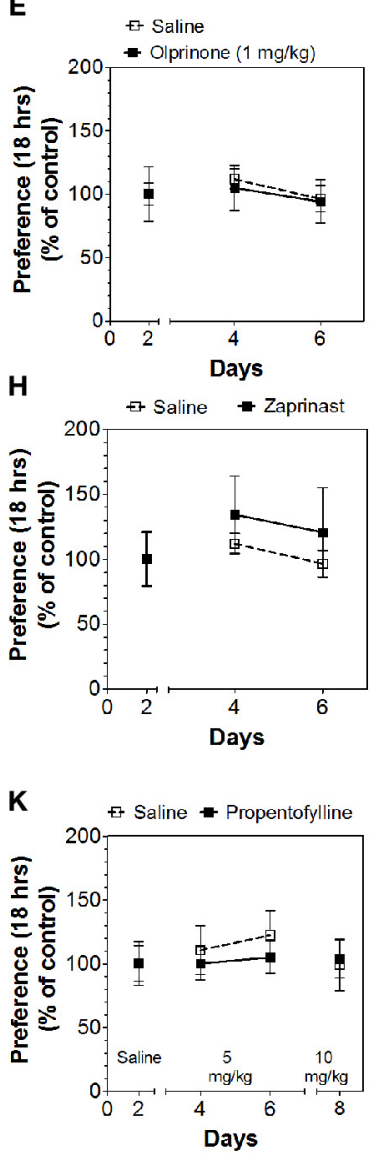

$\mathbf{N}$

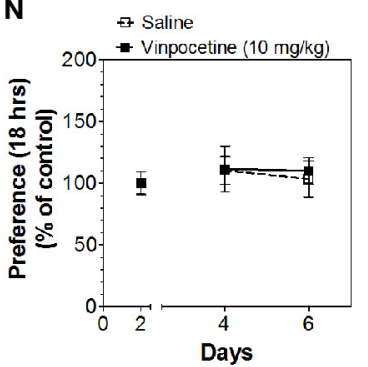

C
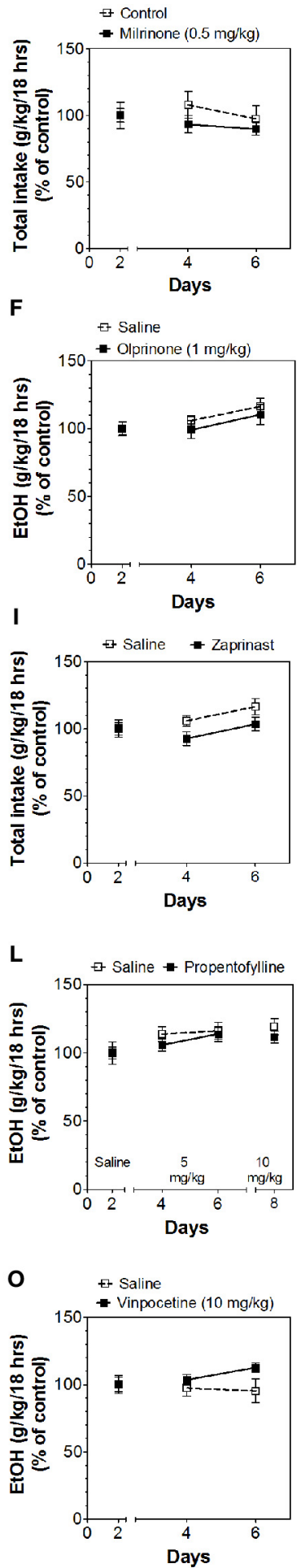

FIGURE 5 | PDE1,3,5 and nonspecific inhibitors do not alter alcohol intake during the last $18 \mathrm{~h}$ of the 24-h two-bottle choice paradigm. Ethanol consumption is presented as $\mathrm{g} / \mathrm{kg} / 18 \mathrm{~h}$ : (A) Milrinone (D) Olprinone (G) Zaprinast (J) Propentofylline (M) Vinpocetine. Preference for ethanol: (B) Milrinone (E) Olprinone (H)
Zaprinast (K) Propentofylline (N) Vinpocetine. Total fluid intake (g/kg/18h): (C) Milrinone (F) Olprinone (I) Zaprinast (L) Propentofylline (O) Vinpocetine. Data were analyzed by Two-Way ANOVA with repeated measures followed by Bonferroni's test for multiple comparisons ( $n=6$ per group; $\mathrm{EtOH}=$ ethanol). 


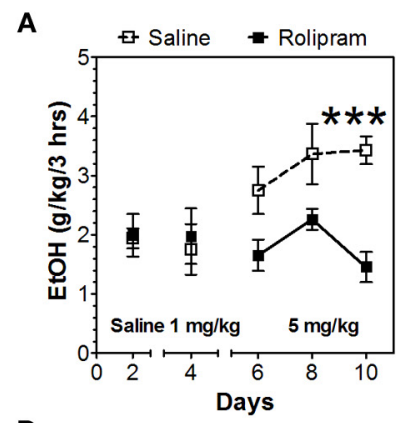

D

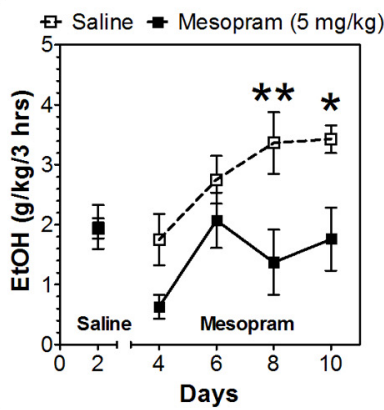

G

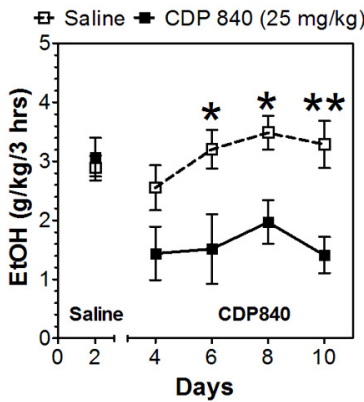

$\mathbf{J}$

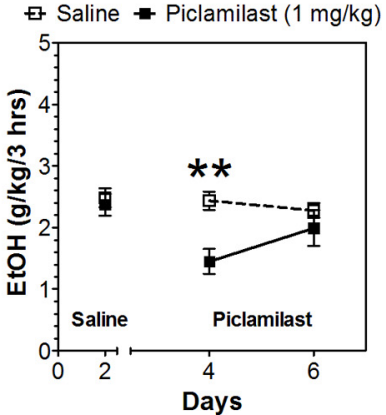

B

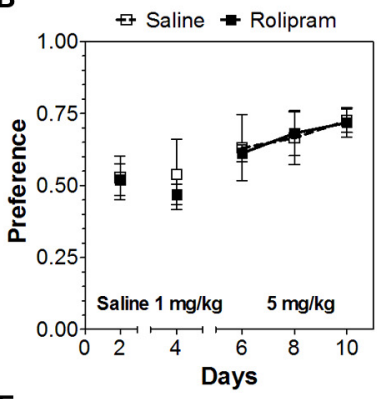

E

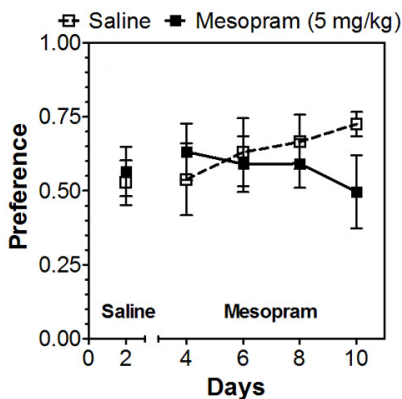

H

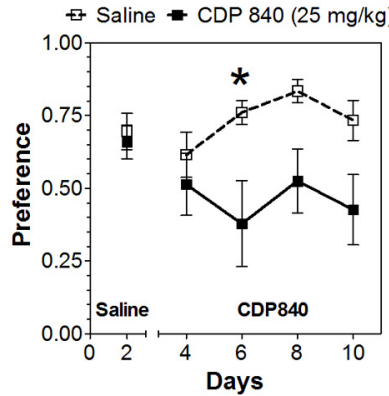

K

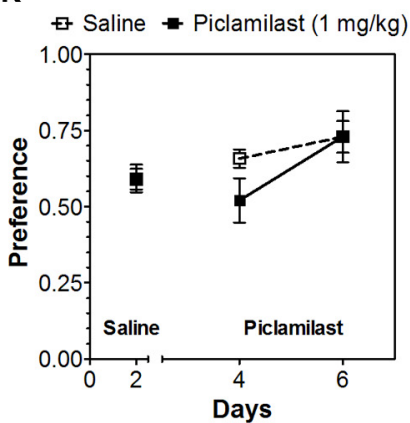

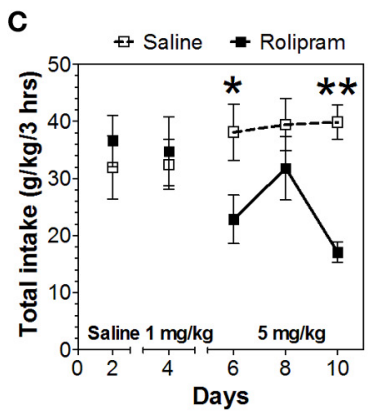

$\mathbf{F}$

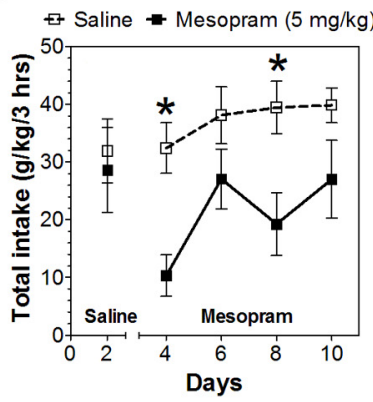

|

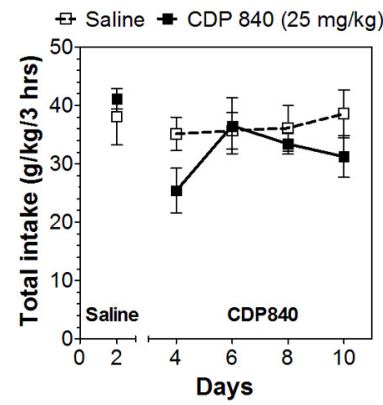

L

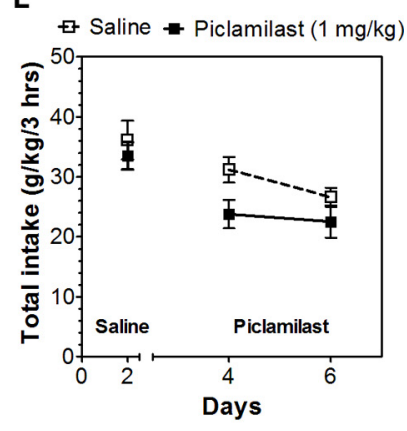

FIGURE 6 | Effects of PDE4 inhibitors on alcohol intake during a limited access (3-h) two-bottle choice Drinking in the Dark test. Ethanol consumption is presented as $\mathrm{g} / \mathrm{kg} / 3 \mathrm{~h}$ : (A) Rolipram (D) Mesopram (G) CDP840 (J) Piclamilast. Preference for ethanol: (B) Rolipram (E) Mesopram (H) CDP840 (K) Piclamilast. Total fluid intake (g/kg/3 h): (C) Rolipram (F) Mesopram (I) CDP840 (L) Piclamilast. Data were analyzed by Two-Way ANOVA with repeated measures followed by Bonferroni's test for multiple comparisons. ${ }^{*} p<0.05 ;{ }^{* *} p<0.01 ;{ }^{* * *} p<0.001$ compared to control $(n=6$ per group; $\mathrm{EtOH}=$ ethanol). et al., 1986). Duplantier et al. (1996) noted a relationship between the high affinity site (in rats) and emesis (in ferrets), and there is a correlation between high affinity binding of denbufylline, rolipram, piclamilast, CDP840, and KF19514 and their emetic activity in the house musk shrew (Hirose et al., 2007). Thus, inhibitors with lower selectivity for PDE4D and lower binding to the high affinity site may reduce the side effects of these drugs.

Given the proposed link between neuroimmune signaling and alcohol consumption and dependence (Harris and Blednov, 2013; Mayfield et al., 2013), PDE inhibitors could potentially decrease alcohol consumption by inhibiting inflammatory signaling. 
Indeed, rolipram dose-dependently reduced LPS-induced production of TNFa in rat brain and microglia (Buttini et al., 1997; Yoshikawa et al., 1999). Furthermore, LPS, pro-inflammatory cytokines, and ethanol all increased the activity of PDE4 in several types of cells (microglia, astrocytes, bronchial epithelial), and these effects were reversed by rolipram (Buttini et al., 1997; Forget et al., 2003; Ghosh et al., 2012).

Our work represents the first comparison of different classes of PDE inhibitors in different ethanol drinking tests in mice with a genetic predisposition for high alcohol consumption. We provide strong evidence for a selective role of PDE4 inhibitors in reducing alcohol consumption and preference. PDE4 inhibitors have also been investigated in animal models of other CNS disorders, and the availability of more selective isoforms devoid of side effects may prove beneficial in the treatment of alcohol abuse and other inflammatory diseases.

In addition to behavioral evidence for specific PDEs in alcohol drinking in rodents, there is evidence for altered expression of PDE genes in mice following chronic ethanol. For example, Pde10 and $P d e 1 b$ were upregulated in mouse prefrontal cortex after chronic ethanol intake (Osterndorff-Kahanek et al., 2013), and $P d e 4 b$ was upregulated while $P d e 10 a$ was downregulated in brains of mice showing a genetic predisposition to high alcohol consumption (Mulligan et al., 2006). Furthermore, the Collaborative Study on the Genetics of Alcoholism (COGA) identified a candidate single nucleotide polymorphism near PDE11A based on differing allele frequencies between alcohol-dependent and control individuals (Johnson et al., 2006). While both mouse and human studies nominate PDE genes, confirmation using multiple datasets combined with behavioral validation will ultimately be important to link them to addiction vulnerability.

\section{AUTHOR CONTRIBUTIONS}

Yuri A. Blednov designed and performed experiments, analyzed data, and wrote the paper; Jillian M. Benavidez and Mendy Black performed experiments; R. Adron Harris designed experiments and wrote the paper.

\section{ACKNOWLEDGMENTS}

Research was supported by NIAAA grants AA06399 and AA013520 (INIA-West Consortium). We thank Dr. Jody Mayfield for helpful comments and editorial assistance.

\section{SUPPLEMENTARY MATERIAL}

The Supplementary Material for this article can be found online at: http://www.frontiersin.org/journal/10.3389/fnins.2014.

\section{9/abstract}

\section{REFERENCES}

Ashton, M. J., Cook, D. C., Fenton, G., Karlsson, J. A., Palfreyman, M. N., Raeburn, D., et al. (1994). Selective type IV phosphodiesterase inhibitors as antiasthmatic agents. The syntheses and biological activities of 3-(cyclopentyloxy)4-methoxybenzamides and analogues. J. Med. Chem. 37, 1696-1703. doi: 10.1021/jm00037a021

Bell, R. L., Lopez, M. F., Cui, C., Egli, M., Johnson, K. W., Franklin, K. M., et al. (2013). Ibudilast reduces alcohol drinking in multiple animal models of alcohol dependence. Addict. Biol. doi: 10.1111/adb.12106. [Epub ahead of print].

Bender, A. T., and Beavo, J. A. (2006). Cyclic nucleotide phosphodiesterases: molecular regulation to clinical use. Pharmacol. Rev. 58, 488-520. doi: $10.1124 /$ pr.58.3.5
Blednov, Y. A., Benavidez, J. M., Geil, C., Perra, S., Morikawa, H., and Harris, R. A. (2011). Activation of inflammatory signaling by lipopolysaccharide produces a prolonged increase of voluntary alcohol intake in mice. Brain Behav. Immun. 25(Suppl. 1), S92-S105. doi: 10.1016/j.bbi.2011.01.008

Blednov, Y. A., Bergeson, S. E., Walker, D., Ferreira, V. M., Kuziel, W. A., and Harris, R. A. (2005). Perturbation of chemokine networks by gene deletion alters the reinforcing actions of ethanol. Behav. Brain Res. 165, 110-125. doi: 10.1016/j.bbr.2005.06.026

Blednov, Y. A., and Harris, R. A. (2008). Metabotropic glutamate receptor 5 (mGluR5) regulation of ethanol sedation, dependence and consumption: relationship to acamprosate actions. Int. J. Neuropsychopharmacol. 11, 775-793. doi: 10.1017/S1461145708008584

Blednov, Y. A., Ponomarev, I., Geil, C., Bergeson, S., Koob, G. F., and Harris, R. A. (2012). Neuroimmune regulation of alcohol consumption: behavioral validation of genes obtained from genomic studies. Addict. Biol. 17, 108-120. doi: 10.1111/j.1369-1600.2010.00284.x

Blednov, Y. A., Stoffel, M., Chang, S. R., and Harris, R. A. (2001). Potassium channels as targets for ethanol: studies of G-protein-coupled inwardly rectifying potassium channel 2 (GIRK2) null mutant mice. J. Pharmacol. Exp. Ther. 298, 521-530.

Bouchery, E. E., Harwood, H. J., Sacks, J. J., Simon, C. J., and Brewer, R. D. (2011). Economic costs of excessive alcohol consumption in the U.S., 2006. Am. J. Prev. Med. 41, 516-524. doi: 10.1016/j.amepre.2011.06.045

Bouza, C., Angeles, M., Munoz, A., and Amate, J. M. (2004). Efficacy and safety of naltrexone and acamprosate in the treatment of alcohol dependence: a systematic review. Addiction 99, 811-828. doi: 10.1111/j.1360-0443.2004. 00763.x

Buttini, M., Mir, A., Appel, K., Wiederhold, K. H., Limonta, S., Gebicke-Haerter, P. J., et al. (1997). Lipopolysaccharide induces expression of tumour necrosis factor alpha in rat brain: inhibition by methylprednisolone and by rolipram. $\mathrm{Br}$. J. Pharmacol. 122, 1483-1489. doi: 10.1038/sj.bjp.0701502

Cherry, J. A., and Davis, R. L. (1999). Cyclic AMP phosphodiesterases are localized in regions of the mouse brain associated with reinforcement, movement, and affect. J. Comp. Neurol. 407, 287-301.

Crabbe, J. C., Harris, R. A., and Koob, G. F. (2011). Preclinical studies of alcohol binge drinking. Ann. N.Y. Acad. Sci. 1216, 24-40. doi: 10.1111/j.17496632.2010.05895.x

Crews, F. T. (2012). Immune function genes, genetics, and the neurobiology of addiction. Alcohol Res. 34, 355-361.

Dinter, H., Tse, J., Halks-Miller, M., Asarnow, D., Onuffer, J., Faulds, D., et al. (2000). The type IV phosphodiesterase specific inhibitor mesopram inhibits experimental autoimmune encephalomyelitis in rodents. J. Neuroimmunol. 108, 136-146. doi: 10.1016/S0165-5728(00)00265-4

Di Paola, R., Mazzon, E., Paterniti, I., Impellizzeri, D., Bramanti, P., and Cuzzocrea, S. (2011). Olprinone, a PDE3 inhibitor, modulates the inflammation associated with myocardial ischemia-reperfusion injury in rats. Eur. J. Pharmacol. 650, 612-620. doi: 10.1016/j.ejphar.2010.10.043

Duplantier, A. J., Biggers, M. S., Chambers, R. J., Cheng, J. B., Cooper, K., Damon, D. B., et al. (1996). Biarylcarboxylic acids and -amides: inhibition of phosphodiesterase type IV versus $[3 \mathrm{H}]$ rolipram binding activity and their relationship to emetic behavior in the ferret. J. Med. Chem. 39, 120-125. doi: 10.1021/jm9505066

Flatscher-Bader, T., Zuvela, N., Landis, N., and Wilce, P. A. (2008). Smoking and alcoholism target genes associated with plasticity and glutamate transmission in the human ventral tegmental area. Hum. Mol. Genet. 17, 38-51. doi: $10.1093 / \mathrm{hmg} / \mathrm{ddm} 283$

Forget, M. A., Sisson, J. H., Spurzem, J. R., and Wyatt, T. A. (2003). Ethanol increases phosphodiesterase 4 activity in bovine bronchial epithelial cells. Alcohol 31, 31-38. doi: 10.1016/j.alcohol.2003.06.005

Genovese, T., Mazzon, E., Paterniti, I., Esposito, E., and Cuzzocrea, S. (2011). Neuroprotective effects of olprinone after cerebral ischemia/reperfusion injury in rats. Neurosci. Lett. 503, 93-99. doi: 10.1016/j.neulet.2011.08.015

Ghosh, M., Garcia-Castillo, D., Aguirre, V., Golshani, R., Atkins, C. M., Bramlett, H. M., et al. (2012). Proinflammatory cytokine regulation of cyclic AMPphosphodiesterase 4 signaling in microglia in vitro and following CNS injury. Glia 60, 1839-1859. doi: 10.1002/glia.22401

Giembycz, M. A. (2008). Can the anti-inflammatory potential of PDE4 inhibitors be realized: guarded optimism or wishful thinking? Br. J. Pharmacol. 155, 288-290. doi: 10.1038/bjp.2008.297 
Halene, T. B., and Siegel, S. J. (2007). PDE inhibitors in psychiatry-future options for dementia, depression and schizophrenia? Drug Discov. Today 12, 870-878. doi: 10.1016/j.drudis.2007.07.023

Harris, R. A., and Blednov, Y. A. (2013). "Neuroimmune genes and alcohol drinking behavior," in Neural-Immune Interactions in Brain Function and Alcohol Related Disorders, eds C. Cui, L. Grandison, and A. Noronha (New York, NY: Springer Science+Business Media), 425-440.

He, J., and Crews, F. T. (2008). Increased MCP-1 and microglia in various regions of the human alcoholic brain. Exp. Neurol. 210, 349-358. doi: 10.1016/j.expneurol.2007.11.017

Heilig, M., and Egli, M. (2006). Pharmacological treatment of alcohol dependence: target symptoms and target mechanisms. Pharmacol. Ther. 111, 855-876. doi: 10.1016/j.pharmthera.2006.02.001

Hirose, R., Manabe, H., Nonaka, H., Yanagawa, K., Akuta, K., Sato, S., et al. (2007). Correlation between emetic effect of phosphodiesterase 4 inhibitors and their occupation of the high-affinity rolipram binding site in Suncus murinus brain. Eur. J. Pharmacol. 573, 93-99. doi: 10.1016/j.ejphar.2007.06.045

Hotte, M., Dauphin, F., Freret, T., Boulouard, M., and Levallet, G. (2012). A biphasic and brain-region selective down-regulation of cyclic adenosine monophosphate concentrations supports object recognition in the rat. PLoS ONE 7:e32244. doi: 10.1371/journal.pone.0032244

Hu, W., Lu, T., Chen, A., Huang, Y., Hansen, R., Chandler, L. J., et al. (2011). Inhibition of phosphodiesterase-4 decreases ethanol intake in mice. Psychopharmacology (Berl). 218, 331-339. doi: 10.1007/s00213-011-2290-8

Jin, S. L., Ding, S. L., and Lin, S. C. (2012). Phosphodiesterase 4 and its inhibitors in inflammatory diseases. Chang Gung Med. J. 35, 197-210.

Johnson, B. A., Rosenthal, N., Capece, J. A., Wiegand, F., Mao, L., Beyers, K., et al. (2007). Topiramate for treating alcohol dependence: a randomized controlled trial. JAMA 298, 1641-1651. doi: 10.1001/jama.298.14.1641

Johnson, C., Drgon, T., Liu, Q. R., Walther, D., Edenberg, H., Rice, J., et al. (2006). Pooled association genome scanning for alcohol dependence using 104,268 SNPs: validation and use to identify alcoholism vulnerability loci in unrelated individuals from the collaborative study on the genetics of alcoholism. Am. J. Med. Genet. B Neuropsychiatr. Genet. 141B, 844-853. doi: 10.1002/ajmg.b. 30346

Kanes, S. J., Tokarczyk, J., Siegel, S. J., Bilker, W., Abel, T., and Kelly, M. P. (2007). Rolipram: a specific phosphodiesterase 4 inhibitor with potential antipsychotic activity. Neuroscience 144, 239-246. doi: 10.1016/j.neuroscience.2006. 09.026

Keravis, T., and Lugnier, C. (2012). Cyclic nucleotide phosphodiesterase (PDE) isozymes as targets of the intracellular signalling network: benefits of PDE inhibitors in various diseases and perspectives for future therapeutic developments. Br. J. Pharmacol. 165, 1288-1305. doi: 10.1111/j.1476-5381.2011. 01729.x

Kim, K. S., Kim, H., Baek, I. S., Lee, K. W., and Han, P. L. (2011). Mice lacking adenylyl cyclase type 5 (AC5) show increased ethanol consumption and reduced ethanol sensitivity. Psychopharmacology (Berl). 215, 391-398. doi: 10.1007/s00213-010-2143-x

Kimpel, M. W., Strother, W. N., McClintick, J. N., Carr, L. G., Liang, T., Edenberg, H. J., et al. (2007). Functional gene expression differences between inbred alcohol-preferring and -non-preferring rats in five brain regions. Alcohol 41, 95-132. doi: 10.1016/j.alcohol.2007.03.003

Knapp, C. M., Foye, M. M., Ciraulo, D. A., and Kornetsky, C. (1999). The type IV phosphodiesterase inhibitors, Ro 20-1724 and rolipram, block the initiation of cocaine self-administration. Pharmacol. Biochem. Behav. 62, 151-158. doi: 10.1016/S0091-3057(98)00154-3

Liu, J., Lewohl, J. M., Harris, R. A., Dodd, P. R., and Mayfield, R. D. (2007). Altered gene expression profiles in the frontal cortex of cirrhotic alcoholics. Alcohol. Clin. Exp. Res. 31, 1460-1466. doi: 10.1111/j.1530-0277.2007. 00444.x

Liu, J., Lewohl, J. M., Harris, R. A., Iyer, V. R., Dodd, P. R., Randall, P. K., et al. (2006). Patterns of gene expression in the frontal cortex discriminate alcoholic from nonalcoholic individuals. Neuropsychopharmacology 31, 1574-1582. doi: 10.1038/sj.npp.1300947

Maas, J. W. Jr., Vogt, S. K., Chan, G. C., Pineda, V. V., Storm, D. R., and Muglia, L. J. (2005). Calcium-stimulated adenylyl cyclases are critical modulators of neuronal ethanol sensitivity. J. Neurosci. 25, 4118-4126. doi: 10.1523/JNEUROSCI.4273-04.2005
Mayfield, J., Ferguson, L., and Harris, R. A. (2013). Neuroimmune signaling: a key component of alcohol abuse. Curr. Opin. Neurobiol. 23, 513-520. doi: 10.1016/j.conb.2013.01.024

Meskini, N., Nemoz, G., Okyayuz-Baklouti, I., Lagarde, M., and Prigent, A. F. (1994). Phosphodiesterase inhibitory profile of some related xanthine derivatives pharmacologically active on the peripheral microcirculation. Biochem. Pharmacol. 47, 781-788. doi: 10.1016/0006-2952(94)90477-4

Mulligan, M. K., Ponomarev, I., Hitzemann, R. J., Belknap, J. K., Tabakoff, B., Harris, R. A., et al. (2006). Toward understanding the genetics of alcohol drinking through transcriptome meta-analysis. Proc. Natl. Acad. Sci. U.S.A. 103, 6368-6373. doi: 10.1073/pnas.0510188103

Nunes, F., Ferreira-Rosa, K., Pereira Mdos, S., Kubrusly, R. C., Manhaes, A. C., Abreu-Villaca, Y., et al. (2011). Acute administration of vinpocetine, a phosphodiesterase type 1 inhibitor, ameliorates hyperactivity in a mice model of fetal alcohol spectrum disorder. Drug Alcohol Depend. 119, 81-87. doi: 10.1016/j.drugalcdep.2011.05.024

Osterndorff-Kahanek, E., Ponomarev, I., Blednov, Y. A., and Harris, R. A. (2013). Gene expression in brain and liver produced by three different regimens of alcohol consumption in mice: comparison with immune activation. PLoS ONE 8:e59870. doi: 10.1371/journal.pone.0059870

Page, C. P., and Spina, D. (2011). Phosphodiesterase inhibitors in the treatment of inflammatory diseases. Handb. Exp. Pharmacol. 391-414. doi: 10.1007/978-3642-17969-3_17

Perry, M. J., O’Connell, J., Walker, C., Crabbe, T., Baldock, D., Russell, A., et al. (1998). CDP840: a novel inhibitor of PDE-4. Cell Biochem. Biophys. 29, 113-132. doi: $10.1007 / \mathrm{BF} 02737831$

Prickaerts, J., Sik, A., Van Staveren, W. C., Koopmans, G., Steinbusch, H. W., Van Der Staay, F. J., et al. (2004). Phosphodiesterase type 5 inhibition improves early memory consolidation of object information. Neurochem. Int. 45, 915-928. doi: 10.1016/j.neuint.2004.03.022

Qin, L., He, J., Hanes, R. N., Pluzarev, O., Hong, J. S., and Crews, F. T. (2008). Increased systemic and brain cytokine production and neuroinflammation by endotoxin following ethanol treatment. J. Neuroinflammation 5, 10. doi: 10.1186/1742-2094-5-10

Raeburn, D., and Karlsson, J. A. (1993). Effects of isoenzyme-selective inhibitors of cyclic nucleotide phosphodiesterase on microvascular leak in guinea pig airways in vivo. J. Pharmacol. Exp. Ther. 267, 1147-1152.

Rhodes, J. S., Best, K., Belknap, J. K., Finn, D. A., and Crabbe, J. C. (2005). Evaluation of a simple model of ethanol drinking to intoxication in C57BL/6J mice. Physiol. Behav. 84, 53-63. doi: 10.1016/j.physbeh.2004.10.007

Saklani, R., Jaggi, A., and Singh, N. (2010). Pharmacological preconditioning by milrinone: memory preserving and neuroprotective effect in ischemia-reperfusion injury in mice. Arch. Pharm. Res. 33, 1049-1057. doi: 10.1007/s12272-010-0711-6

Schneider, H. H., Schmiechen, R., Brezinski, M., and Seidler, J. (1986). Stereospecific binding of the antidepressant rolipram to brain protein structures. Eur. J. Pharmacol. 127, 105-115. doi: 10.1016/0014-2999(86)90210-4

Shahid, M., Van Amsterdam, R. G., De Boer, J., Ten Berge, R. E., Nicholson, C. D., and Zaagsma, J. (1991). The presence of five cyclic nucleotide phosphodiesterase isoenzyme activities in bovine tracheal smooth muscle and the functional effects of selective inhibitors. Br. J. Pharmacol. 104, 471-477. doi: 10.1111/j.1476-5381.1991.tb12453.x

Smith, D. L., Pozueta, J., Gong, B., Arancio, O., and Shelanski, M. (2009). Reversal of long-term dendritic spine alterations in Alzheimer disease models. Proc. Natl. Acad. Sci. U.S.A. 106, 16877-16882. doi: 10.1073/pnas.0908706106

Sugioka, M., Ito, M., Masuoka, H., Ichikawa, K., Konishi, T., Tanaka, T., et al. (1994). Identification and characterization of isoenzymes of cyclic nucleotide phosphodiesterase in human kidney and heart, and the effects of new cardiotonic agents on these isoenzymes. Naunyn Schmiedebergs Arch. Pharmacol. 350, 284-293. doi: 10.1007/BF00175034

Thompson, B. E., Sachs, B. D., Kantak, K. M., and Cherry, J. A. (2004). The Type IV phosphodiesterase inhibitor rolipram interferes with drug-induced conditioned place preference but not immediate early gene induction in mice. Eur. J. Neurosci. 19, 2561-2568. doi: 10.1111/j.0953-816X.2004.03357.x

Wen, R. T., Zhang, M., Qin, W. J., Liu, Q., Wang, W. P., Lawrence, A. J., et al. (2012). The phosphodiesterase-4 (PDE4) inhibitor rolipram decreases ethanol seeking and consumption in alcohol-preferring Fawn-Hooded rats. Alcohol. Clin. Exp. Res. 36, 2157-2167. doi: 10.1111/j.1530-0277.2012.01845.x 
Xiao, L., O’Callaghan, J. P., and O’Donnell, J. M. (2011). Effects of repeated treatment with phosphodiesterase-4 inhibitors on cAMP signaling, hippocampal cell proliferation, and behavior in the forced-swim test. J. Pharmacol. Exp. Ther. 338, 641-647. doi: 10.1124/jpet.111. 179358

Yamada, K., Tanaka, T., Senzaki, K., Kameyama, T., and Nabeshima, T. (1998). Propentofylline improves learning and memory deficits in rats induced by beta-amyloid protein-(1-40). Eur. J. Pharmacol. 349, 15-22. doi: 10.1016/S00142999(98)00166-6

Yoshikawa, M., Suzumura, A., Tamaru, T., Takayanagi, T., and Sawada, M. (1999). Effects of phosphodiesterase inhibitors on cytokine production by microglia. Mult. Scler. 5, 126-133. doi: 10.1177/135245859900 500210

Zhu, J., Mix, E., and Winblad, B. (2001). The antidepressant and antiinflammatory effects of rolipram in the central nervous system. CNS Drug Rev. 7, 387-398. doi: 10.1111/j.1527-3458.2001.tb00206.x
Conflict of Interest Statement: The authors declare that the research was conducted in the absence of any commercial or financial relationships that could be construed as a potential conflict of interest.

Received: 14 March 2014; accepted: 08 May 2014; published online: 27 May 2014. Citation: Blednov YA, Benavidez JM, Black M and Harris RA (2014) Inhibition of phosphodiesterase 4 reduces ethanol intake and preference in C57BL/6J mice. Front. Neurosci. 8:129. doi: 10.3389/fnins.2014.00129

This article was submitted to Neuropharmacology, a section of the journal Frontiers in Neuroscience.

Copyright (C) 2014 Blednov, Benavidez, Black and Harris. This is an open-access article distributed under the terms of the Creative Commons Attribution License (CC BY). The use, distribution or reproduction in other forums is permitted, provided the original author(s) or licensor are credited and that the original publication in this journal is cited, in accordance with accepted academic practice. No use, distribution or reproduction is permitted which does not comply with these terms. 